\title{
«MÁS DE UN VIZCAÍNO». LECTURAS DE LOS SERVICIOS DE HOMBRES Y LOS MARCOS FORALES DE LOS TERRITORIOS VASCOS EN LA ÉPOCA DE LOS AUSTRIAS: EL MINISTERIO DEL CONDE-DUQUE DE OLIVARES, 1621-1643
}

\author{
Imanol Merino MaliLlos \\ Universidad del País Vasco/Euskal Herriko Unibertsitatea
}

\begin{abstract}
RESUMEn. Estudiamos las lecturas de las obligaciones referentes a la contribución a la defensa del conjunto de la monarquía española de los Austrias partiendo de los ordenamientos jurídicos de los territorios de vascos. Tras acercarnos a los trabajos más recientes sobre la materia, analizaremos las lecturas realizadas tanto por las instituciones locales como por la corona. Nos centraremos en un marco cronológico crítico, como fue el ministerio del conde-duque de Olivares, dado que las crecientes necesidades bélicas de la monarquía conllevaron un incremento en las peticiones de soldados, que culminaron con el sitio y socorro de Fuenterrabía de 1638. Prestaremos así especial atención a lo sucedido hasta entonces e inmediatamente después, ya que se produjo una tensión entre la corona - que cuestionaba tanto las normas jurídicas como las prácticas de reclutamientos-y las instituciones locales y los naturales.
\end{abstract}

Palabras clave: siglos XVI y XVII, monarquía española, servicios de hombres, territorios vascos, fueros

ABstract. This paper addresses the interpretations concerning the participation of the Basque Provinces in the defence of the Monarchy, based on the local codes of law. First, we expose the main researches on this subject of the most recent historiography. Second, we compare the interpretations that the local institutions and the crown did in the Early Modern centuries. We focus on a specific period, the ministry of the Count Duke of Olivares (1621-1643), and in a particular moment, the siege of Fuenterrabia (1638) and what happened in the next months. A lapse of time when there was a clash of interpretations of the military duties of the Basque peoples between the Crown and the local institutions, and how the recruitment should be conduct.

Keywords: $16^{\text {th }}$ and $17^{\text {th }}$ centuries, Spanish Monarchy, recruitment, local codes of law, Basque Provincesistration

Recibido: 30-01-2021 . Aceptado: 16-03-2021 . imanol.merino@ehu.eus 
En 1723 LA Diputación de VizCAYa retomó una iniciativa, planteada ya a comienzos del siglo XVII, ordenando que se plantara un nuevo árbol y se erigiese una cruz donde antaño había estado el árbol Malato que, «por el transcurso de tienpo se abia perdido» ${ }^{1}$. La medida recuperada a comienzos del siglo XVIII era una resolución político-jurídica y militarmente relevante en el plano simbólico. El árbol «perdido»y su emplazamiento marcaban el límite de las obligaciones militares de los vizcaínos, al menos en lo referente a quién debía de costearlas. Así había quedado recogido en el título sexto del que sería denominado Fuero Viejo de Vizcaya, redactado en 1452 (Líbano, 2016, p. 220), de donde pasó al conocido como Fuero Nuevo de Vizcaya, escrito en 1526, en su título I, denominado De los privilegios de Vizcaya, ley V, titulada: «Cómo los vizcaínos siendo llamados por el señor han de ir a servir, y en qué casos les han de dar sueldo» (Areitio, 1977, p. 18).

El simbolismo de ese árbol, ubicado fuera los límites de Vizcaya, se remontaba a la fundación mítica del Señorío. Hasta ese enclave habrían seguido los vizcaínos a su primer — y legendario - señor, Jaun Zuria — Señor Blanco, en euskera-, en su persecución a las tropas del rey de León tras la batalla de Arrigorriaga, que habría tenido lugar en el siglo IX. El caudillo vizcaíno hizo una marca en su tronco, de ahí que se le denominara «enfermo» o «malato». El vínculo con aquel primer señor lo entroncaba con el elenco de relatos míticos que se habían asentado como fundamentos históricos de los privilegios colectivos vizcaínos (Mañaricúa, 2012, pp. 137-165; Monreal, 1980, pp. 1003-1004). El «malato» sin embargo no era el único árbol con relevancia simbólica para el señorío y sus naturales, aunque sí era el único que se hallaba fuera de sus límites. Vizcaya, al igual que muchas comunidades jurídico-políticas de la época, contaba con varios árboles con carga simbólica. Es el caso del roble de Guernica, bajo el que se reunían sus Juntas Generales (Caro, 1989).

\section{Los servicios de hombres de las provincias vascas y sus mar- cos forales en los siglos xvi y xvII: cuestiones iniciales}

El señorío de Vizcaya fue configurándose en los siglos modernos como una de las provincias denominadas cántabras y, más adelante, vascongadas, junto con Álava y Guipúzcoa. Estas tres constituyen el ámbito geográfico a considerar a la hora de abordar la formación y desarrollo del hipotético modelo vasco de aportaciones de hombres a la defensa de la monarquía en nuestro marco cronológico. Procede sin embargo significar algunas precauciones que matizan en cierta medida lo que aca-

1 Diputación, Bilbao, 4 de noviembre de 1723, (en VV.AA., 1994-2009, Juntas y Regimientos de Bizkaia. Actas, t. XXIII, Bilbao, Juntas Generales de Bizkaia, pp. 455-456; a partir de ahora citaremos estas actas como JJRRB) y Regimiento General, Bilbao, 7-17 de mayo de 1603, en $J J R R B$, t. VII, p. 77, de donde extractamos esas palabras. 
bamos de señalar, dado que hacemos referencia a tres cuerpos políticos diferentes y complejos, que carecían de unidad jurídica o de instituciones comunes, más allá de las posibles concurrencias en determinados casos donde estaban en juego intereses compartidos. Ello marca una diferencia radical con otras realidades y prácticas estudiadas en este monográfico, pues se centrarán en reinos que disponían de marcos institucionales y jurídicos generales que les conferían una unidad, caso de Valencia, Aragón, Navarra o Galicia, por citar cuatro reinos englobados en dos de las coronas ibéricas. Por eso los autores podrán hablar de ellos como modelos concretos, y de su encuadre en un marco general.

En consecuencia, sería erróneo hablar de un único modelo vasco, en abstracto. Más bien debemos hablar en plural de modelos vascos, o incluso de la existencia de un modelo vizcaíno, otro guipuzcoano y un tercero alavés, ya que el cuerpo político de cada uno de ellos contaba con sus respectivos ordenamientos jurídicos, que servían como marco diferenciado para establecer las obligaciones militares de sus naturales. En realidad, constituían dos provincias y un señorío, contando cada entidad con sus instituciones particulares y propios sus corpus jurídicos generales. Estos iura propria les diferenciaban o establecían particularidades tanto entre sí como con el derecho general del reino de Castilla, y si bien se ha hecho hincapié en esta última vertiente, lo cierto es que las diferencias jurídicas entre ellas también eran sustanciales. Así, el derecho foral que se consolidó en Vizcaya fue eminentemente de infanzonazgo o tierra llana, frente a las 21 villas y ciudad que conservarán sus derechos urbanos, aunque algunos de los privilegios contenidos en el Fuero vizcaíno fueran extensivos a los núcleos urbanos y sus originarios. Por el contrario, los derechos alavés y guipuzcoano fueron fruto o estuvieron fuertemente condicionados por la aparición y el papel preponderante de las villas, siendo en origen cuadernos de las hermandades controladas por aquellas, de ahí que recibieran las denominaciones de ordenanzas (Ayerbe, 2019, pp. 11-33). Además, Vizcaya y sus naturales gozaban de un juez y una sala particulares en la chancillería de Valladolid: el juez mayor y la sala de Vizcaya (Martín, 1968). Un foro privativo en un alto tribunal del que no disponían los otros dos. En suma, existían similitudes, pero también diferencias entre los tres ámbitos señalados en este período.

Conviene advertir que los marcos jurídicos de las tres provincias vascas en los siglos XVI y XVII no sólo eran diferentes en tanto que entidades jurídico-políticas diversas, sino que también eran cambiantes en lo temporal, pues sus normas jurídicas fueron objeto de sincrónicas y diacrónicas interpretaciones y reinterpretaciones, principalmente realizadas por juristas, como era norma en la cultura jurídica de la época: la del ius commune (Martínez, 2016). Estas interpretaciones eran llevadas a cabo por juristas y letrados y por los órganos de gobierno y justicia en los propios territorios y fuera de ellos, como ha sido puesto de manifiesto para el caso vizcaíno y 
los autores castellanos que estudiaron sus Fueros (García, 2017, pp. 58-160). Por lo tanto, mientras el contenido formal del ordenamiento local, el texto escrito e impreso — en caso de estarlo - permanecía formalmente inalterado, la concreción material de los fueros variaba en base a las interpretaciones, condicionadas tanto por principios generales como por esos derechos y realidades locales, pues la jurisprudencia del derecho común debía hacerse cargo «obligadamente» de que este era ante todo «derecho local, derecho de usos y autoridades locales» (Clavero, 2012, p. 698). Esto, unido a la evolución institucional, ha dado pie a la historiografía a formular diversas propuestas de periodización de la foralidad (López, 1991; Laborda, 2012, pp. 15-17 y pp. 575-585). No hay que olvidar, sin embargo, que durante el periodo que centra nuestro estudio, el ministerio del conde-duque de Olivares, Vizcaya era la única de las tres entidades que contaba con un ordenamiento jurídico provincial de naturaleza foral recopilado, confirmado por el rey e impreso. Y que, asimismo, el señorío defendió que sus privilegios eran en algunos aspectos cualitativamente superiores a los de sus vecinos, como se puso de manifiesto cuando se barajó la posibilidad de hacer un frente común como reacción al estanco de la sal que intentaba imponer la corona (Porres, 2007, pp. 349-353)2.

Pese a ello, había elementos compartidos entre algunos o los tres territorios que disponían de instituciones provinciales propias, y carecían de representación en las cortes del reino. Los naturales de dos de ellos disfrutaban de hidalguía universal, naturaleza nobiliaria íntimamente ligada a sus servicios militares, pues estaba sustentada en ellos y en la defensa de la frontera. Los vizcaínos disponían de confirmación real, ya que su hidalguía estaba recogida en el Fuero Nuevo (1527), aunque esto no significó que no fuese cuestionada tanto por los juristas y los tribunales reales como por los habitantes de las otras regiones. Precisamente en el principal texto doctrinal en defensa de la nobleza vizcaína, redactado para hacer frente a su cuestionamiento por el fiscal García Saavedra (c. 1588), su autor, el licenciado Andrés de Poza, señalaba como uno de sus fundamentos el que «según atestigua la historia hispana, apenas en parte alguna de tierra o mar se asumió expedición en la que el inquebrantable cántabro no se haya manchado de sangre» (Poza, 1997, pp. 222-251). En Guipúzcoa, el asunto de la hidalguía no es cuestión pacífica, y es que si bien hubo un cierto consenso historiográfico en señalar que fue confirmada por Felipe III en 1608 y 1610, algunas investigaciones recientes adelantan la obtención de la hidalguía universal al año 1527 , si bien se trataría de un reconocimiento implícito, en base a la potestad de los municipios guipuzcoanos de controlar los avecindamientos (Soria, 2006; Aguinagalde, 2016; una lectura crítica de la misma en Díaz de Durana, 2020, pp. 292-301). Aun así en la época seguía siendo materia problemática, dado que en el reinado que 
centra nuestra investigación las chancillerías tuvieron que recibir y guardar la provisión real que establecía que los guipuzcoanos, que «con el estímulo de su nobleza han acudido y acuden con tanto fruto a nuestro servicio» real, fuesen tenidos por hidalgos ${ }^{3}$. En Álava, por su parte, esta condición no era universal para sus naturales, excepción hecha de algún valle del norte de la provincia.

También la «ubicación» jurídico-política de cada uno de los tres territorios vascos en Castilla y en la monarquía española era particular (Arrieta, Gil y Morales, 2017). En ellos se había consolidado desde finales del siglo xv una lectura pactista de su engarce en el conjunto. Los marcos privilegiados de estas provincias, sustentados en el plano discursivo por mitos y voluntarias entregas o capitulaciones, tenían para la corona dos pilares fundamentales en sus condiciones propias, tales como la pobreza de la tierra o su función defensiva. Esta última se escindía en dos planos. Por un lado, y al igual que otras regiones, principalmente las fronterizas, entre las obligaciones de sus naturales estaba la de defender su propio territorio. Por otro lado, como vasallos del rey también debían prestarle auxilium por tierra o por mar. Dos dimensiones de los servicios militares que constituirían lo que la historiografía ha denominado «armamento foral» $\mathrm{y}$ 《armamento exterior», respectivamente; conceptos cuyo uso se ha generalizado a partir de las décadas de 1970 y 1980, período en que la atención de los investigadores se centró en la perspectiva económico-fiscal de la aportación de hombres a los ejércitos y armadas reales. En esos trabajos remarcaron la importancia de las relaciones rey-provincias, su encuadre en la monarquía española y particularmente su especificidad fiscal, subrayando la relevancia de su función defensiva y contraponiendo los servicios destinados fuera de ellas - el mencionado «armamento exterior» - a las obligaciones de autodefensa, el llamado «armamento foral» (Bilbao, 1991; Mugartegui, 1990, pp. 40-52).

En los últimos años, diversos investigadores han estudiado el origen y evolución de las contiendas bélicas y los mecanismos de reclutamiento de tropas. Aun cuando no se encuadra en nuestro marco cronológico, hemos de que destacar la labor que están llevando a cabo algunos medievalistas al analizar los enfrentamientos banderizos, el papel de los servicios militares como transformadores de la situación de esos territorios y el engarce foral de los mismos en el conjunto de Castilla en los siglos bajomedievales (Vitores, 2019, pp. 623-749; Etxebarria y Fernández de Larrea, 2020). Para los siglos modernos destacan los trabajos de Susana Truchuelo, quien ha estudiado el modelo de aportación de hombres y de defensa de los territorios vascos, con especial atención a la organización militar de Guipúzcoa y su evolución, que ha comparado con el caso alavés (Truchuelo, 2004, pp. 215-269; ID., 2007 y 2013). En lo relativo a esta última provincia, la investigación ha primado la lectura en clave

3 Traslado de una real provisión relativa a las hidalguías de la provincia de Guipúzcoa, Valladolid, 11 de abril de 1639, en Archivo de la Real Chancillería de Valladolid, Cédulas y Pragmáticas, caja 9,2. 
fiscal, aunque también se han realizado trabajos pormenorizados sobre algunos períodos (Porres, 2003, pp. 276-288; Bombín, 1999; Sánchez, 1999). La labor de Lourdes Soria (2007) merece una mención especial, pues ha analizado el fenómeno desde la perspectiva jurídica en los siglos XVIII y, principalmente, en el XIX, atendiendo a la potestad reglamentaria de las instituciones locales. Otros autores también se han acercado al mundo de los servicios de hombres, con el objetivo de analizar el papel de los militares y su promoción en el servicio del rey (Angulo, 2016).

Este recorrido nos ha posibilitado señalar la presencia de determinados investigadores en el tema y permite advertir al lector una ausencia: la de Vizcaya. Frente a la referida importancia de las contiendas y enfrentamientos armados bajomedievales y a la participación vizcaína en las campañas reales y en la defensa de la corona de Castilla, las aportaciones de hombres a la monarquía durante los siglos XVI y XVII apenas si han atraído la atención de los historiadores. Dentro de la historiografía vasca más reciente, pocos investigadores se han centrado en Vizcaya, y cuando lo han hecho, ha sido para estudiar otras materias como la evolución socio-política, y durante otro periodo histórico, pese a que en trabajos recientes lo vizcaíno está cobrando más interés, dado que, además de resultar defensivamente relevante, tenía un ordenamiento jurídico mejor perfilado.

Para el análisis del modelo de aportación de hombres de los territorios vascos a los contingentes reales durante el periodo barroco es necesario referenciarlos con los estudios sobre la organización militar de la monarquía española, en general, y de Castilla, en particular. Sin embargo, esto no ha sido posible hasta fechas recientes, en buena medida por la ausencia de interlocutores, ya que hubo escasos estudios sobre reclutamiento en los reinos ibéricos hasta la eclosión de la historia militar como disciplina en las últimas décadas (Jiménez, 2015). Sólo en fechas recientes se ha trazado el mapa completo de los diversos mecanismos de reclutamiento en Castilla, gracias a los trabajos de Antonio José Rodríguez Hernández y Antonio Jiménez Estrella, quienes han estudiado las lógicas y obligaciones de aportaciones defensivas de las provincias vascas, encuadrándolas en el conjunto de Castilla (Jiménez, 2009, pp. 73-84; Rodríguez, 2011, pp. 213-282).

Valiéndonos de los logros de los trabajos citados, en este artículo vamos a centrarnos en el estudio de los denominados «armamentos exteriores», y más en concreto, en la participación de las tres provincias en la defensa del conjunto mediante los servicios de hombres para los contingentes terrestres, eligiendo para ello un contexto crítico. La presencia de oriundos de los territorios vascos en los contingentes reales del periodo era relevante, como reflejaron multitud de textos literarios contemporáneos, en los que participaba algún vizcaíno — en sentido amplio, entendido como sinónimo de vascoparlante y, por lo tanto, originario de Vizcaya, Álava o Guipúzcoa-, hidalgo y soldado (Legarda, 1953, pp. 23-35 y pp. 308-325). El refranero 
castellano así lo recogía, como queda reflejado en la recopilación hecha por Gonzalo Correas, publicada en 1627. En ella aparecen varios refranes referentes a Vizcaya - en su significado amplio - y sus naturales, entre los que se encuentra el siguiente: «En nao y en castillo, no más de un vizcaíno», añadiendo a renglón seguido el motivo del mismo: «porque son caprichosos y se aúnan» (Correas, 1906, p. 116). En este artículo nos centraremos en esos vizcaínos que sirvieron en tierra, en castillos y, sobre todo, en los ejércitos.

\section{Una(s) lectura(s) de los servicios de los territorios vascos de la época de los Austrias. El ministerio del conde-duque de Olivares (1621-1643): todo converge en Fuenterrabía}

Escogemos a continuación un momento significativo y concreto de la historia militar de la monarquía española para ver las lecturas que hicieron de las obligaciones militares, en general, y de la aportación de hombres a los contingentes reales, en particular, tanto las instituciones locales - en nuestro caso, las vascas-, como la corona. El contexto en que dicho momento acaeció fue de tensiones en torno a los servicios militares entonces, resultando a su vez a posteriori un lugar de recuerdo para los defensores del sistema de reclutamiento posibilitado por los marcos jurídico-institucionales. Así sucedió con la villa de Fuenterrabía y su sitio y socorro en 1638, que fue - junto con las consecuencias posteriores al mismo - uno de los principales acontecimientos bélicos que tuvieron lugar en la región durante el periodo de los Austrias.

En el espacio de Fuenterrabía y la frontera del Bidasoa con el reino de Francia convergían múltiples actores, intereses y jurisdicciones (Truchuelo, 2017; Chavarría, 2012). La población era una villa guipuzcoana con una relación tensa con los órganos de gobierno del resto de la provincia. La existencia de un presidio y de una autoridad militar regia y de contingentes de hombres sometidos a la jurisdicción militar hacían del lugar un foco de tensiones. Asimismo, la participación de los naturales de los territorios vascos en su defensa, e incluso su entrada y sometimiento a los mandos militares designados por el rey, eran cuestiones disputadas. En el caso de Guipúzcoa, si bien se trataba de su defensa, rehusaba el sometimiento de sus naturales a una autoridad militar designada por las autoridades reales, dado que contaba con sus propios mandos militares. Para Álava y Vizcaya el auxilio de esa villa suponía la emergencia de un espacio de tensión entre los dos armamentos, puesto que implicaba la salida de hombres fuera de sus respectivos límites. El señorío de Vizcaya no concebía Fuenterrabía como propia defensa, ya que para él primaba la protección de la costa vizcaína y sus once puertos, si bien estaba dispuesto a enviar hombres a la frontera terrestre 
en caso de extrema necessitas. Álava, por su parte, pareció más dispuesta a exceder sus límites y posibilitar que sus naturales participasen en la defensa de la frontera guipuzcoana (Truchuelo, 2007, pp. 262-266).

El comienzo de la guerra con Francia en 1635 mudó este panorama, ya que a partir de entonces perdió nitidez la clara diferencia entre los servicios exteriores de gente de tierra y la autodefensa. Para los primeros se había consolidado un procedimiento que comenzaba con el envío de una misiva, presentada por el delegado regio - el corregidor en Vizcaya y Guipúzcoa, el diputado general en Álava-, ante los procuradores reunidos en las Juntas Generales. Estas respondían bien accediendo a la solicitud o bien rechazando los términos en los que se había presentado - número, destino u otras condiciones - o rehusando hacer el servicio, abriendo en los dos últimos casos una fase de intensas negociaciones. Hemos utilizado el verbo consolidar por dos razones: primero, porque no era mecanismo que se encontrase escrito en los ordenamientos jurídicos de los territorios vascos de la época, lo que no fue óbice para que fuera estableciéndose y definiéndose como el procedimiento de reclutamiento de soldados en esas provincias. Y, segundo, porque en este contexto crítico, con unas crecientes necesidades de recursos humanos para la guerra, las negativas y reticencias de las instituciones vascas a conceder los servicios reclamados en los términos demandados, llevaron a la corona a inquirir y a cuestionar los fundamentos jurídicos de esta fórmula.

Los órganos de gobierno local, principalmente las asambleas denominadas Juntas Generales, jugaban un papel esencial en este procedimiento de «reclutamiento intermediario» (Thompson, 1981, pp. 145-151). En este punto se hace necesario exponer algunos rasgos sobre su evolución. En Vizcaya, esas asambleas fueron perdiendo espacio político y jurídico propio en favor primero del regimiento general y, después, del regimiento particular, que devino finalmente en la diputación (Zabala, 2014). En Guipúzcoa se dio un fenómeno semejante, con un creciente protagonismo del mismo órgano colegiado reducido, llegando a existir una versión especializada llamada diputación a guerra (Ruiz, 1997, pp. 206-209). Consideramos interesante apuntar que, además de los factores locales que favorecieron la aparición y consolidación de estos órganos reducidos, la corona también pudo favorecer su creciente papel, ya que la interlocución con ellos y sus posibles actuaciones eran menos complejas que con las asambleas generales, dado que participaban menos actores. En este sentido, y para el caso que estudiamos, no conviene olvidar que todavía resonaban los «ecos de la matxinada» de 1631-1634 y que un cierto temor a las Juntas Generales pervivía en el recuerdo tanto de los ministros reales como de muchos miembros de la oligarquía vizcaína (Merino, 2017a). El proyecto del estanco de la sal y la oposición en los territorios vascos, que alcanzó tintes violentos en Vizcaya, también puso en evidencia las limitadas posibilidades de actuación y poder tanto de los ministros 
reales en la región como de las élites locales a la hora de controlar a los junteros y la población local.

Al igual que sucedía en otras regiones de la monarquía, la negociación de los servicios de hombres era un espacio de oportunidades para esas oligarquías, quienes podían obtener mercedes y cargos por su labor mediadora (Saavedra, 2017), bien mediante su incardinación en el servicio militar o mediante la obtención de mercedes y recompensas como contraprestación a los servicios que prestaban en la provincia. En el primer caso, las patentes en blanco para la designación de los mandos militares de las unidades levantadas para el servicio real adquirieron una gran importancia para las élites vascas y su promoción en los ejércitos (Rodríguez, 2007 y 2012, pp. 440-442). En el segundo caso, la negociación de esos servicios solía ir acompañada de una política selectiva del rey a la hora de otorgar mercedes y recompensas para aquellos que se significasen en la consecución de los designios regios, o cuya preeminencia hiciese recomendable que se les tuviera en estima y fueran recompensados (Angulo, 2015; Imízcoz, 2009). Pero la corona también podía hacer la lectura inversa de esta política de do ut des basada en los servicios militares. Si la concesión de estos favorecía la integración de esas élites en la monarquía, la negativa a realizarlos podía perjudicarlas, sobre todo si para fundarla incidían remarcar el régimen jurídico diferenciado de la provincia. Así lo manifestó el propio Felipe IV, quien, exasperado por la negativa de las entidades territoriales vascas a conceder la cantidad de hombres requerida para los contingentes reales en los términos planteados, llegó a sugerir que Vizcaya y Guipúzcoa fuesen considerados «separados en todo y por todo», lo que implicaba que sus naturales no disfrutasen de cargos y honores en Castilla ${ }^{4}$.

Conviene reparar en un aspecto esencial como era el conocimiento por parte de la del rey y sus ministros de la situación y de algunos elementos fundamentales de los territorios. Cuestiones que eran muy relevantes respecto al cuánto y al cómo proceder al reclutamiento de las tropas, siendo necesario conocer previamente los recursos humanos y económicos, así como los derechos locales. En cuanto a lo primero, su conocimiento de la región era muy limitado. Comenzando por los recursos humanos y económicos, a principios de la década de 1630, al querer imponer el estanco sobre la sal y los acopios forzosos ni siquiera pudo saber cuál era la población de Guipúzcoa y Vizcaya (VV.AA., 2015, pp. 3-31). Y en lo que al marco jurídico se refiere, tenemos que detenernos en el conocimiento que las autoridades reales tenían de los ordenamientos jurídicos de cada una de las entidades territoriales que componían la monarquía. Sobre esto, diversas fuentes podían proporcionarle información, como es el caso de los naturales que servían en la administración real y los ministros que habían ejercido cargos en o relacionados con ese territorio o, y en caso de que estu-

4 Rescripto de Felipe IV en la consulta del consejo de Guerra, Madrid, 7 de abril de 1639, en Archivo General de Simancas (en adelante AGS), Guerra y Marina (en adelante GYM), leg. 1265. 
vieran disponibles, la consulta de textos jurídicos. En este punto procede retomar una idea planteada al inicio de este trabajo: que, en la época de Felipe IV, de las tres provincias que analizamos sólo Vizcaya contaba con una recopilación foral confirmada por el monarca y que podía correr impresa en la que pudiera leerse las obligaciones militares de sus naturales, y en cuya difusión las instituciones del señorío pusieron especial empeño (Merino, 2018) $)^{5}$.

Las provincias vascas no eran sino tres de las múltiples entidades territoriales que componían la corona de Castilla y la monarquía española. En su seno había una diversidad jurídico-institucional que se proyectaba también sobre los ámbitos fiscal y militar, y si bien subyacían principios comunes, la plasmación y concreción de las distintas obligaciones militares de los naturales variaban en cada caso. Con todo, la especificidad de cada una, fruto de su particular incorporación a Castilla, no estaba perfectamente definida, tal y como podemos observar en al menos dos documentos referidos al sostenimiento de la defensa del conjunto a comienzos del reinado de Felipe IV.

El primero de ellos data de 1622, momento en el que la apertura de frentes y la amenaza de nuevas guerras llevaron a trazar proyectos para garantizar la defensa de la monarquía. Para ello, en octubre de ese año la junta Grande de Reformación remitió a las ciudades con voto en cortes varias propuestas, entre las que incluía que «las demás probinçias» - Aragón, Portugal, Navarra, Vizcaya y Guipúzcoa, se concretaba-, debían acudir a la defensa del conjunto con el socorro de soldados. Esto debían hacerlo tanto porque era «común el benefiçio», como porque «en este género de socorros no tienen fuero, ni leyes que los exenten, ni fuera justo que les aprovecharan, quando los tubieran» (González, 1932, p. 406). Estas palabras nos permiten insistir en el desconocimiento existente en torno a los ordenamientos jurídicos locales al que nos hemos referido, dado que un mismo órgano afirmaba que esos territorios no disponían de privilegios de esa naturaleza, para, a renglón seguido, señalar que sí podían tenerlos. Una — aparente - contradicción no determinante para la corona, ya que primaban los principios jurídicos y metajurídicos sobre los privilegios locales en aras de la defensa común.

Pocos años después, en 1626, Vizcaya y Guipúzcoa perdían esa sustantividad en el segundo documento que exponemos, y que fue uno de los principales proyectos

$5 \quad$ En el caso alavés, el historiador clásico Landázuri refería la que sería conocida como voluntaria unión o entrega de la cofradía de Arriaga (1332), que acabaría convirtiéndose en sustento jurídicohistórico de los privilegios de la provincia, y que fue confirmada por los sucesivos reyes. Entre ellos, Felipe IV (Landázuri, 1799, pp. 221-241). Sí disponía de un cuaderno de ordenanzas de la Hermandad alavesa, centrado en la organización institucional y la administración de justicia, confirmado y que corrió impreso (Ayerbe, 2019, pp. 61-99). En lo que a Guipúzcoa se refiere, la provincia buscó insistentemente la confirmación regia de su ordenamiento durante el reinado de Felipe IV, sin obtenerla (Aramburu, 2014, pp. 76-92). 
trazados para garantizar la defensa de la monarquía: la Unión de Armas. En su texto no aparecían diferenciadas, sino que - debemos concluir - quedaban integradas en Castilla e Indias, que debían sostener 44.000 hombres (Elliott, de la Peña y Negredo, 2013, pp. 167-183). El fracaso de dicho proyecto y la creciente amenaza de guerra con Francia incrementaron las necesidades de hombres por parte del rey y sus ministros, que tuvieron que recurrir a diferentes expedientes para llevar a cabo nuevos reclutamientos en la década de 1630. Así, se procuró el aumento del servicio de los aristócratas mediante las coronelías, se firmaron asientos y se buscó la implicación de las entidades territoriales a través de sus instituciones, como la leva forzosa para los presidios, aprobada por las cortes de Castilla, y de la que quedaron fueran las provincias vascas (Rodríguez, 2017, p. 159).

En lo que a los territorios vascos en concreto se refiere, en la década de 1620 y primeros años de la siguiente la corona y las instituciones locales se centraron en defender la frontera, en especial cuando la amenaza de un ataque enemigo se cernía sobre Fuenterrabía, como sucedió en 1625 y 1632. Pero nuevamente surgían las disputas sobre la participación de vizcaínos, guipuzcoanos y alaveses y su sometimiento a mandos ajenos a su provincia. Las autoridades reales requirieron el concurso de los naturales, pero las instituciones tendieron a responder de manera evasiva o negativa. Guipúzcoa no quería situar a sus hombres bajo una autoridad militar ajena al cuerpo provincial. Una idea que se vislumbra en lo expuesto por un conocedor de la realidad local como Martín de Aróztegui en 1629, quien desaconsejaba solicitar hombres para Fuenterrabía o Irún, ya que Guipúzcoa sufriría un gran desgaste por ello, y que, caso de ser necesario, en veinticuatro horas podrían reunirse sus vecinos para acudir a la frontera. Aróztegui apuntaba también que las autoridades guipuzcoanas no estaban acostumbradas «a encerrar su gente en Fuenterrabía, sino tenerla en campaña» ${ }^{6}$. Álava, por su parte, respondió al requerimiento real de 1632 argumentando que el servicio de hombres que solía dar para la defensa de Fuenterrabía era voluntario y otorgado «si lo pedía la necesidad y lo permitían las fuerças» ${ }^{7}$. El señorío de Vizcaya, ante esa misma situación, optó por priorizar su autodefensa antes que la de la frontera del Bidasoa ${ }^{8}$.

Tanto en las provincias vascas como en los demás lugares de Castilla debieron realizar en esos años ingentes esfuerzos económicos para afrontar los gastos que imponía la guerra (Gelabert, 1997, pp. 81-126). En las primeras se solicitaron, al igual que en otros territorios castellanos, donativos, y también se procuró hacerles extensivo el estanco de la sal, lo que fue intensamente contestado, teniendo su manifestación

\footnotetext{
6 Consulta del consejo de Guerra, Madrid, 22 de junio de 1629, en AGS, GYM, leg. 993.

7 Junta General, Zurbano, 4-7 de mayo de 1632 (VV.AA., 1994, Actas de las Juntas Generales de Álava, t. XV, Vitoria, Juntas Generales de Álava, Vitoria, pp. 363-365).

8 Junta General, Guernica, 28 y 29 de septiembre de 1632, en JJRRB, t. XI, pp. 126 y ss.
} 
más violenta en Vizcaya. Fue aquí donde se fraguó un discurso de oposición a esa nueva medida fiscal que se sustentaba principalmente en los servicios militares que habían prestado y prestaban la provincia y sus naturales ${ }^{9}$. Las alteraciones ocurridas entonces condicionaron lo sucedido en la segunda mitad de la década de 1630, primero, porque la corona mostró su firme voluntad de implicar a los territorios vascos y de una manera más intensa en el sostenimiento del conjunto de la monarquía. Y segundo, porque el recuerdo vivido u oído o leído de los disturbios habría de condicionar la visión de los ministros reales, reacios en adelante a soliviantar a los naturales.

La implicación fiscal vino acompañada en aquel contexto de peticiones de hombres para la defensa fronteriza y con destino a las guerras fuera de la península. En 1631 las autoridades reales solicitaron hombres para acompanar al cardenal-infante. Para Vizcaya la petición fue de 200 hombres, si bien el señorío concedió 250, añadiendo una cláusula de salvaguarda foral, que señalaba que:

todo lo qual sea y se entienda sin perjuiçio de los fueros, esençiones, franquezas y libertades, buenos hussos y costumbres deste dicho Señorio de Vizcaya y por particulares razones y fundamentos que para ello ha tenido, por esta vez, sin que pueda causar consequençia para otras en adelante. ${ }^{10}$

Este párrafo condensa los límites de la concesión, pero también apunta los marcos de la misma. La primera parte de este breve texto nos remite al límite jurídico del servicio: el Fuero de Vizcaya y a la lectura e interpretación del servicio prestado. La segunda, al alcance de las negociaciones, pues lo entonces acordado no obligaba a futuro. Era una concesión sin obligación de remplazar las tropas ni consecuencias a futuro; es decir, que una nueva petición conllevaría una nueva negociación.

Junto a los límites impuestos por los ordenamientos particulares, otros factores institucionales y políticos condicionaron el proceso de negociación. En este, una figura desempeñaba un rol fundamental: el delegado regio en cada partido. Tanto en Vizcaya como en Guipúzcoa era el corregidor, un cargo gestado y generalizado en Castilla, pero cuyos cometidos tenían matices específicos en ambas provincias. Las limitaciones a las que se veía sometido el delegado del rey en Guipúzcoa en lo referente a los reclutamientos fueron señaladas por el titular del cargo en una carta escrita en 1634. Su misiva comenzaba recordando que «el gobierno de este corregimiento no es como el de otros de esta corona $\rangle^{11}$. Su vertebración jurídico-institucional impedía aplicar lo practicado en otros partidos, que eran gobernados y dirigidos desde la ciu-

9 Un ejemplo de ello es el memorial presentado por las Encartaciones, conservado en British Library, General Reference Collection, 765.i.6, doc. 12.

10 Junta General, Guernica, 24 y 25 de junio de 1631, en JJRRB, t. XI, pp. 41-42.

11 Esta y las siguientes citas proceden de la copia de la carta del corregidor Luis de Castilla y Villagutierre, San Sebastián, 15 de abril de 1634, en AGS, GYM, leg. 1095. 
dad cabecera, donde residía el corregidor. En Guipúzcoa no existía tal preminencia, sino que había muchas y diversas villas, y el órgano delegado de la asamblea general, la diputación, tenía escasa capacidad de decisión. Todo llevaba forzosamente a las Juntas Generales, con los gastos y complicaciones que ello implicaba. Y, a modo de colofón, según señalaba esa carta, los junteros acudían con poderes limitados, no llevando «voto sino decisivo de negar», lo que hacía inútil cualquier argumentación. Como inútil resultaba también, en su opinión, recurrir a las élites locales,

porque los muy poderosos y hacendados no son los más bien queridos ni tienen mano, los demás no quieren hacer empeño ni se atreven a proponer tales materias ni a que parezca se hacen dueños dellas, porque luego lo atribuyen los demás o a sus pretensiones particulares o a ser ministros y criados de Su Md.

La guerra que dio comienzo al año siguiente entre Francia y España marcó un punto de inflexión en la frontera pirenaica occidental, desdibujándose los límites entre los servicios exteriores y la defensa del propio territorio, ya que la guerra se iba a desarrollar en terreno propio (Maffi, 2014, pp. 21-99). Durante los primeros años se sucedieron servicios concedidos o en casos denegados, y con negociaciones no exentas de tensiones. Esto llevó a la corona a cuestionar el sistema de aportación de hombres de las provincias vascas y los límites a las obligaciones que pretendían tener de servir en los ejércitos reales. Preocupado por las dificultades que estaba encontrando, el monarca preguntó por los privilegios que alegaban las entidades territoriales a la hora de rechazar los servicios que se les requerían. Así, en el marco de las campañas protagonizadas por el ejército de Labort en 1637, Felipe IV había ordenado al consejo de la Cámara de Castilla que escrutase:

si tiene entendido que las provincias de Álava y Guipúzcoa y reino de Navarra tienen fueros, o privilegios para que si para los accidentes de guerra y defensa de mis reinos les pidiere número de gente el que yo señalare y hubiere menester pagado por mi cuenta se pueden excusar de dármele quedando en [?] su voluntad el cumplirlo o dejarlo de hacer, o si les puedo obligar. ${ }^{12}$

Este texto nos permite apuntar dos cuestiones de especial importancia. En primer lugar, el creciente protagonismo de los consejeros de jurisdicción ordinaria y de gracia en los asuntos bélicos. El consejo de Castilla y el de su Cámara, como veremos, fueron los órganos que se pronunciaron respecto a las obligaciones de las provincias vascas. En el arcano mundo de los derechos territoriales hispánicos, los

12 Despacho del rey al arzobispo de Granada, presidente del consejo de Castilla, Madrid, 30 de marzo de 1637, en Archivo Histórico Nacional (en adelante AHN), Consejo Suprimidos (en adelante CCSS), leg. 13197. 
jueces y magistrados que estaban al frente de los tribunales cobraron una especial importancia. Fueron miembros de los principales consejos reales y de otros tribunales, y eran juristas que se habían formado en las universidades hispanas, lo que les había permitido conocer los fundamentos del mundo jurídico del ius commune. $\mathrm{Su}$ posterior carrera en la administración de justicia les hacía entrar en contacto con los ordenamientos jurídicos de los territorios bajo la jurisdicción de sus tribunales. Como las cuestiones militares se movían entre las obligaciones de los vasallos y los marcos jurídicos locales, la corona comisionó múltiples letrados, miembros de los tribunales ordinarios, para la obtención de recursos para la guerra (Mackay, 2007, pp. 31-73). En segundo lugar, se evidencia que el rey no tenía intención de sobrepasar los ordenamientos jurídicos que se había comprometido a respetar, prefiriendo emplear para lograrlo medios suaves, aunque quería saber cuáles eran sus límites y hasta qué punto podía obligarles a plegarse a los mismos, «en caso que pusiesen alguna escusa en obedecer» ${ }^{13}$. Una cuestión englobada dentro del debate jurídico-político, de hondo calado en la época, entre la obediencia ejecutiva y la obediencia negociada (Cárceles, 1997; Valladares, 2012).

Todos estos factores convergieron en 1638, cuando las tropas francesas volvieron a atacar Fuenterrabía. El sitio de la villa dio lugar a una movilización extraordinaria de recursos para su socorro, como se encargaron de recopilar, publicar y publicitar tras el mismo varios actores participantes (Díaz, 2003). Entonces, Guipúzcoa, Álava y Vizcaya, al igual que otras entidades territoriales, enviaron una gran cantidad de tropas para defender la frontera y socorrer la población sitiada (Truchuelo, 2015). El inopinado éxito en el auxilio fue visto por el Felipe IV y sus ministros como el punto de partida de un nuevo modelo militar de defensa, cimentado sobre la colaboración de distintas entidades territoriales, cuyas aportaciones y sustento de unidades militares podían llegar a ser un pilar fundamental del ejército real, y para lograrlo era preciso conocer los límites que al respecto establecían los marcos jurídicos locales.

En el invierno de 1638-1639 la situación de guerra abierta y de frente activo dio pie a otros asuntos que ocasionaban tensiones jurídico-militares en el área pirenaica occidental. Por lo tanto, el cuestionamiento de los preceptos de los ordenamientos jurídicos locales no se ciñó al modo en que tenía lugar la aportación de hombres a los ejércitos reales, sino a otro aspecto que devino sumamente grave, el alojamiento de las tropas procedentes tanto de otros lugares de la monarquía como de otros parajes (Merino, 2017b). Esto constituyó otro factor de tensión social y jurídica, ya que había que discutir los términos de dichos alojamientos, que obligaban a detraer recursos esenciales para la población al objeto de satisfacer las necesidades de los soldados.

13 Despacho del rey al arzobispo de Granada, presidente del consejo de Castilla, Madrid, 30 de marzo 1637, en Archivo Histórico Nacional (en adelante AHN), CCSS, leg. 13197. 
Para encauzar estas y otras materias relacionadas con la guerra en la frontera pirenaica occidental, la corona creó en octubre de 1638 un órgano colegiado que quedaría radicado en la ciudad alavesa de Vitoria. A partir de finales de ese año sería denominado Consejo de Cantabria, dado que estaría vinculado al ejército que se estaba configurando en la región, uno de los primeros permanentes en suelo ibérico, en el cual se integrarían las mencionadas tropas: el Ejército de Cantabria. La creación de ese consejo se enmarcó en la dinámica de desconcentración administrativa que se desplegó ante las limitaciones que mostraba el sistema tejido en décadas anteriores y las necesidades que imponía la guerra en la península ibérica (Merino, 2017c). Fruto de la potestas extraordinaria del monarca, este órgano, al igual que las juntas establecidas en la corte, tenía como objetivo, según autores como Juan Salgado Araújo, servir de complemento sublime a la justicia y al restablecimiento del orden, un cometido para el que las vías ordinarias, los consejos, se mostraban en aquel momento incapaces de lograr (Hespanha, 1994-1995, pp. 70-71). Varios aspectos de ese consejo resultan de interés, comenzando por su nombre, que hacía referencia a los míticos cántabros, quienes en época antigua habían resistido los envites de los soldados romanos y habían preferido suicidarse a rendirse. Cantabria era una denominación que en la época abrazaba a los tres territorios vascos, merced al desarrollo, consolidación y difusión del mito conocido como vasco-cantabrismo (Arrieta, 2014). Dicha asimilación de las tres provincias bajo el apellido de Cantabria había sido impulsada especialmente por Guipúzcoa, aunque Vizcaya y Álava no dejaron de estar interesadas en ella.

Una de las principales funciones de los consejeros desplazados a Vitoria era obtener los hombres que determinaran el consejo de Guerra, la junta de Ejecución y los demás órganos radicados en la corte encargados de gestionar el conflicto. El cometido del consejo de Cantabria era adaptar sus resoluciones a las circunstancias concretas, sin desvirtuar los objetivos originales, para lo que se le dotó de la autoridad de algunos consejos reales, principalmente de los de Guerra, de Castilla y su Cámara. Relativo al reclutamiento de hombres para el ejército de Cantabria debía obtener las cantidades fijadas, e igualmente escrutar los fueros y privilegios locales para establecer los límites de sus obligaciones y los mecanismos de aportación de gente para la guerra con destino a los ejércitos reales. Asimismo, debía inquirir el papel que en ella tenían las instituciones locales y la necesidad de su aprobación. En suma, solventar la cuestión planteada por el Felipe IV en 1637.

Las indagaciones llevadas a cabo por el consejo de Cantabria en sus primeros meses de existencia, en paralelo al escrutinio realizado por el consejo de la Cámara de Castilla, quedaron recogidas en un parecer elaborado por el protonotario Jerónimo de Villanueva a finales de 1638, donde se exponía que: 
la mano de que en esta parte esta [provincia] ha usado no se funda en privilegio sino en costumbre en que con buena maña se ha ido adelantando la provincia [de Guipúzcoa] con la asistencia de personas que la han favorecido. ${ }^{14}$

Pocos meses después, en abril de 1639, el consejo de Castilla, tras analizar el ordenamiento jurídico y los derechos de Vizcaya y Guipúzcoa, reiteró que la mecánica de los servicios y la negociación con las instituciones no era preceptiva, pues el rey «no necesita del consentimiento de estas provincias para sacar y levantar la gente necesaria», dado que en el soberano residía «la suprema potestad para hacer guerra y paz sin intervención de los vasallos», así como «ajustar los medios para la defensa y la ofensa $»^{15}$. En cuanto a los privilegios, los consejeros y el monarca hacían una lectura restrictiva de los mismos, concluyendo que se reducía a un asunto de remuneraciones y salarios, y que estos eran la condición suficiente en orden a obtener los hombres requeridos. Todo lo que supusiese excederla no era sino un «medio suave», como lo era encauzar la petición a través de los órganos provinciales. En este punto tanto Felipe IV como el consejo de Castilla coincidían prácticamente en lo escrito por este último al afirmar que el Fuero «no solo les excusa, antes presupone la obligación pagándoles V. Majd. sueldo» ${ }^{16}$. Ahora bien, desde las instituciones vascas se hacía una lectura muy diferente. Para estas, el pago de un estipendio a los hombres resultaba una condición necesaria para que el servicio tuviera lugar - aunque ocasionalmente un servicio exterior pudiera ser costeado por el territorio--, si bien no era suficiente. Previamente debía existir una negociación al objeto de que, atendiendo a las necesidades y situaciones locales, se alcanzase la cantidad de hombres necesaria. Y ahí radicaba uno de los puntos de fricción entre ambas lecturas: lo dispuesto en los ordenamientos jurídicos — significativamente en el Fuero de Vizcaya - o defendido por las instituciones locales era un punto de llegada para la corona, mientras que para estas era el punto de partida de las negociaciones.

El éxito de Fuenterrabía llevó a revivir el espíritu — que no la fórmula ni escala — de la Unión de Armas, al hacerse un llamamiento a la aportación de hombres por parte de distintas entidades territoriales ibéricas, lo que permitió contraponer modelos y comparar las distintas actitudes. El propio Felipe IV pudo así contrastar el comportamiento de los naturales de Aragón y sus instituciones con los de los territorios vascos, denunciando que estos últimos se abrogaban «privilegios, cuando los

14 Voto del protonotario Jerónimo de Villanueva, sobre las actuaciones del consejo de Cantabria, s.f. (diciembre de 1638), en AGS, GYM, leg. 1275.

15 Consulta del consejo de Castilla, Madrid, 16 de abril de 1639, en AHN, CCSS, leg. 7155.

16 Consulta del consejo de Castilla, Madrid, 23 de marzo de 1639, en AHN, CCSS, leg. 7155. Unos días antes, el propio monarca se había expresado en términos semejantes. Consulta del consejo de Estado y Guerra, Madrid, 28 de febrero de 1639, en AGS, GYM, leg. 1265 
aragoneses se están ajustando a cuanto es mi antojo, cuanto y más a mi voluntad $\rangle^{17}$. A ello se añadía que el destino de los hombres era un ejército que había de encargarse de defender la frontera pirenaica occidental. Las cortes y los órganos de gobierno de los distintos reinos ibéricos de la monarquía estaban aportando hombres para la guerra. En el caso de Navarra, sus cortes permitieron en 1642, y por primera vez, que sus tercios, levantados para la defensa del propio reino, saliesen fuera de los confines del mismo, para participar en la guerra de Cataluña (Floristán, 1984).

Tabla 1. Servicios exteriores de hombres negociados con las instituciones del señorío de Vizcaya, 1635-1643

\begin{tabular}{|c|c|c|c|c|}
\hline Año & $\begin{array}{l}\text { Cantidad } \\
\text { solicitada }\end{array}$ & Destino & Respuesta del señorío & $\begin{array}{l}\text { Cantidad } \\
\text { concedida }\end{array}$ \\
\hline 1635 & & Servir donde se le ordenare & Prevenida & \\
\hline \multirow[t]{2}{*}{1636} & 400 infantes & Socorrer al cardenal-infante & Concedido & \\
\hline & 600 infantes & Para lo que mande el virrey & Denegado & \\
\hline \multirow[t]{3}{*}{1637} & 600 infantes & Ejército de Labort & $\begin{array}{l}\text { Unirlo a los } 400 \text { de Flandes y formar } \\
\text { un Tercio. Se incrementa la cifra. }\end{array}$ & 1.400 \\
\hline & 400 marineros & $\begin{array}{l}\text { Colaboración con la leva que hace } \\
\text { el veedor Irazagorría }\end{array}$ & & \\
\hline & & Presto para acudir a la frontera & Se acuda cuando haya aviso & \\
\hline \multirow[t]{6}{*}{1638} & & Presto para su defensa & Concedido & \\
\hline & 2.500 infantes & Defensa de Guipúzcoa & Se conceden 600 & \\
\hline & Infantes & $\begin{array}{l}\text { Defensa de Guipúzcoa — con } \\
\text { petición de la provincia— }\end{array}$ & $\begin{array}{l}\text { Se concede un tercio de } 1.000- \\
\text { incluidos los supra } 600-\end{array}$ & 1.000 \\
\hline & Soldados de mar & Armada de Lope de Hoces & & \\
\hline & 50 Infantes & Coronelía del conde-duque & Concedido & 50 \\
\hline & 400 Infantes & Ejército de Cantabria & Concedido & 400 \\
\hline 1639 & 1.000 hombres & Armada & Imposible dadas las circunstancias & \\
\hline \multirow[t]{2}{*}{1640} & 50 infantes & Coronelía del conde-duque & Concedido & 50 \\
\hline & Infantes & $\begin{array}{l}\text { Llenar el número de } 400 \text { soldados } \\
\text { del ejército real }\end{array}$ & Se conceden 200 como nuevo servicio & 200 \\
\hline 1641 & Infantes & Ejército real & $\begin{array}{l}\text { Concedido, pero para reclutar fuera } \\
\text { de Vizcaya }\end{array}$ & 400 \\
\hline \multirow[t]{2}{*}{1642} & Infantes & Jornada de Aragón & Concedido & 200 \\
\hline & 200 hombres & Presidio de San Sebastián & El señorío no tiene obligación & \\
\hline \multirow[t]{2}{*}{1643} & 200 infantes & Socorro de Navarra o Guipúzcoa & Concedido & 200 \\
\hline & 100 infantes & Ejército de Aragón & $\begin{array}{l}\text { Denegado por los } 200 \text { infantes } \\
\text { concedidos }\end{array}$ & \\
\hline $\begin{array}{l}\text { Total } \\
\text { cuantificable }\end{array}$ & 6.500 & & & 3.900 \\
\hline
\end{tabular}

Fuente: JJRRB, tt. XI-XIII. En cursiva, algunos otros servicios significativos.

17 Consulta del consejo de Guerra, Madrid, 7 de abril de 1639, en AGS, GYM, leg. 1265. 
Los territorios vascos también se sumaron a los ejércitos reales fruto de las negociaciones de los servicios realizadas en los años posteriores al sitio de Fuenterrabía. Pese a las alternativas que se barajaron, las necesidades que imponía la guerra llevaron a la corona a aceptar el medio de los servicios como el único que, dentro de las premisas militares y de los marcos jurídico-institucionales existentes, garantizaba la obtención de las cantidades necesitadas. Encauzadas las demandas a través del consejo de Cantabria, fructificaron mediante sucesivas negociaciones con las Juntas Generales y órganos de gobierno locales, los cuales respondieron con concesiones y negativas, como se puede comprobar a través de los datos de Vizcaya (véase tabla 1). Los acuerdos se fundaban no tanto en los ordenamientos jurídicos, si bien se apelaba a las limitaciones impuestas por ellos, como en el contexto socio-económico del territorio y su necesidad de autodefensa, y con ello de la salvaguarda de la frontera, así como del desgaste que habían producido los servicios prestados en años anteriores y las levas de marineros que llevaron a cabo algunos asentistas (Merino, 2017a, pp. 164-166).

Una destacada figura de los últimos años del valimiento del conde-duque de Olivares nos ofrece una interesante referencia epilogal. Tal es el caso de Juan Bautista de Larrea, un destacado jurista de la época, cuya vida y obra han sido estudiadas por Paola Volpini (2010), y que participó en esas negociaciones con las entidades de los territorios vascos como miembro del consejo de Cantabria.

Formado en la Universidad de Salamanca, tras trabajar como oidor en la chancillería de Granada accedió a diversos cargos en los órganos centrales de la monarquía, siendo nombrado miembro del consejo de Castilla en 1642. Desde sus diversos cargos Larrea defendió los intereses y derechos del rey y la autoridad de sus ministros. A su dilatada trayectoria como servidor de Felipe IV añadía un componente relevante para nuestro estudio pues, aun habiendo nacido en Madrid, era de origen vizcaíno, y dueño de la casa solar de los Larrea en Echano - Vizcaya- Tal vez por su interés particular en los asuntos de su tierra realizó unos comentarios sobre los Fueros de Vizcaya, que no han sido localizados, y que le valieron ser considerado el más relevante «comentarista a este cuerpo de fueros vizcaínos» (Frankenau, 1993, pp. 460-463). Pero sí disponemos de los apuntes que hizo sobre dicho ordenamiento en su obra Allegationum fiscalium. Un trabajo publicado en dos volúmenes, editados en 1642 - el primero- y 1645 - el segundo-, de cuyo éxito dan cuenta las tres reediciones que conoció en el siglo XVII. En dicha obra, entre otras muchas materias, reflexionó sobre cuándo los vasallos debían seguir al rey en la guerra (Allegatio LXII, en Larrea, 1665, pp. 310-314). Tras defender su obligación y recoger que «necessitas careat lege», desgranaba un caso que conocía de primera mano, el de los «Bizcainos», explicando para ello las diversas obligaciones recogidas en el Fuero de Vizcaya, señalando el árbol Malato como límite estipendiario y afirmando que, pese 
a lo dispuestos en el Fuero y a la condición hidalga de los vizcaínos, «cum publica vrget necessitas», estos estaban dispuestos a renunciar a sus privilegios e inmunidades y acudir al servicio del monarca a su costa. Una disposición que habían mostrado, según recogía Larrea, durante el sitio de Fuenterrabía de 1638.

\section{Reflexiones finales: la memoria del árbol Malato}

Juan Bautista de Larrea recurría a los vizcaínos como exponentes de una obligación y de un marco privilegiado que podía ser traspasado por una comunidad cuando la necessitas lo requería. Ligaba así unos principios con un ordenamiento —el Fuero de Vizcaya-, ejemplificándolo con lo acontecido en un suceso concreto -el asedio y la defensa de la villa de Fuenterrabía.

Los principios de la cultura jurídico-militar latente - necessitas, lealtad, obligaciones militares, defensa y autodefensa-, las normas jurídicas de carácter general y los ordenamientos jurídicos locales, como el Fuero de Vizcaya, servían de base sobre la que construir la tercera dimensión, la concreción del servicio. Esta, además, estaba condicionada por el desenvolvimiento particular de cada región y la situación de la monarquía, así como de los actores que intervenían. Los marcos jurídicos y los privilegios de las provincias vascas eran particulares en lo referente a las cuestiones militares, aunque en este punto hubiese similitudes tanto entre ellos como con lo que sucedía en los otros territorios.

Hemos insistido en la importancia de la impresión y difusión del Fuero Nuevo de Vizcaya, recopilado a comienzos de la era de los Austrias. Acudamos ahora al ordenamiento jurídico de la vecina Guipúzcoa, cuya — nueva - recopilación foral fue redactada, confirmada e impresa a finales del siglo XVII. La reformulación de sus ordenanzas, que habían sido redactadas en 1583, concretaba en su título XXIV, «De las levantadas y cosas de guerra», ley I, «que los de esta provincia no salgan de ella sin ser primero pagados de su salario» ${ }^{18}$. Una norma semejante a la del Fuero Nuevo de Vizcaya, aunque sin rasgos propios, como la referencia al árbol Malato o la concreción de la cantidad salarial a percibir por los que salieran. Este título y ley de las ordenanzas fueron incorporados a la Nueva Recopilación de Guipúzcoa, pero introduciéndose unos términos significativos, que, si bien pudieron estar presentes en otros documentos, no era así en el texto de 1583:

Pero como en estas era precisso se observasse con los Cavalleros Hijosdalgo naturales, vecinos y moradores de la Provincia, lo que es conforme á su Fuero y á los Privilegios de que siempre han gozado, han tenido por bien los Catolicos Reyes de

18 Recopilación de las Leyes y Ordenanzas de Guipúzcoa, Manuscrito, Tolosa, 15 de octubre de 1583, en Biblioteca Nacional de España, MSS/10463, fol. 122v. 
España de guardarselos, mandando que se les pague su sueldo por el tiempo que voluntariamente sirviessen fuera de su tierra, de orden de la Provincia y á instancia de Sus Magestades, (Aramburu, 2014, p. 636).

Las palabras señaladas en cursiva inciden en la necesidad de contar con la aquiescencia de los naturales e, igualmente, con la participación de la provincia. La obligatoriedad o la voluntariedad sobre la que se había cuestionado al monarca en 1637 y la costumbre que había «denunciado» el protonotario en 1638 quedaban de este modo elucidadas y enmarcadas en el ordenamiento jurídico guipuzcoano a finales del siglo mediante su inserción en la mencionada recopilación.

La concreción de la voluntaria participación de los naturales encauzada por la provincia en los contingentes terrestres reales fuera de los límites de aquella se realizaría, ora por la costumbre ora por lo recogido en los textos forales - aunque todo ello escrutado y cuestionado, como hemos visto-, a través de las negociaciones llevadas a cabo con las instituciones locales. En lo referido al periodo de los Austrias, estaríamos ante la historia de una negociación dentro de los marcos impuestos por las necesidades de la guerra, los ordenamientos jurídicos y por la cultura jurídica imperante. En este punto, el caso de estos tres territorios no distaría de lo sucedido en otras realidades peninsulares, como el reino de Valencia, donde se sucedían negociaciones concretas dentro de una lógica constitucional (Pardo, 2001, pp. 431-435).

La historiografía ha insistido en la importancia de las claves relacionales y el papel de las oligarquías a la hora de reconstruir esta negociación, pero no podemos olvidar que la actuación de estas últimas estaba limitada por las estructuras y dinámicas económicas, sociales y jurídico-institucionales de cada territorio, y la posible contestación popular que los servicios prestados pudiesen provocar. En lo referente al aspecto jurídico, hemos de subrayar la importancia tanto del conocimiento como del desconocimiento por parte del rey y sus ministros de las complejas realidades de los territorios de los que se debían obtener los hombres. La corona negociaba en ocasiones con ellos a tientas, sin tener una imagen precisa de su realidad, lo que hacía necesario que recurriese a actores locales, no sólo por su capacidad de movilización, sino también por su conocimiento del terreno en sus múltiples dimensiones, entre ellos, significativamente, la jurídica.

Los marcos jurídicos y su función defensiva, unidos a las constantes levas de marineros, y a otras circunstancias propias, propiciaron que el mecanismo de aportación de hombres a los contingentes terrestres del ejército real que se consolidó en los territorios vascos fuese el de los servicios canalizados por las instituciones locales. Como se ha apuntado, un mecanismo compartido con otras entidades territoriales dentro de Castilla y de la monarquía española durante los siglos XVI y XVII, aunque con especificidades, como las señaladas por el corregidor guipuzcoano en 1634. Por 
lo tanto, la clave del sistema de aportación de hombres a los ejércitos reales se encontraría en su pervivencia posterior, en la que tendrían un rol esencial unas instituciones provinciales capaces interpretar y defender una determinada lectura de los privilegios. Una fórmula que, al igual que el modelo de aportación de hombres, evolucionó sobre la base de las distintas lecturas que se hicieron de los derechos locales, las cuales estuvieron condicionadas a su vez por el contexto general y la evolución de la cultura jurídica. Pero la norma y el límite marcado por el árbol Malato para Vizcaya y sus naturales seguían estando presentes, razón por la cual en pleno siglo XVIII su diputación consideró necesario replantarlo y preservar su memoria. Más aún, para hacer frente a las lecturas críticas y a los cuestionamientos explícitos de sus derechos y privilegios, desde el ámbito vasco se esgrimirían, primero, y se blandirían, después, los servicios prestados por los naturales y vehiculados por las instituciones locales, para defender su vigencia y capacidad de adaptación. Eran el estandarte enarbolado para demostrar la importancia de cada uno de los territorios y sus naturales en la protección militar de la monarquía, y para defender los marcos jurídicos y privilegios, tal y como puede observarse en lo referente a la hidalguía universal de vizcaínos y guipuzcoanos, algo que fue remarcado por el licenciado Poza en su trabajo sobre la defensa de la nobleza de los primeros, y que quedó recogido en la documentación referente a los segundos. De ahí que, pese a las recomendaciones del refranero castellano, en los castillos - y en los ejércitos - de los monarcas hispanos, hubiese más de un vizcaíno.

\section{AGRADECIMIENTOS}

Este trabajo ha sido elaborado dentro del proyecto MINECO «Unión, vinculación y pertenencia a la Monarquía española (siglos XVI-XVIII)» (Ref. DER2017-83881-C21-P), que coordina Jon Arrieta Alberdi en la UPV/EHU. La edición de este trabajo ha sido posible gracias a la ayuda del Programa de Grupos de Potencial Crecemento concedida por la Consellería de Cultura, Educación e Universidade da Xunta de Galicia al GI-1921 de la USC (Referencia: GPC, ED 431B 2021/06). 


\section{Bibliografía}

Aguinagalde, Francisco Borja de (2016), «La sociedad vasca y sus élites (siglo XI1500), y la formulación de la hidalguía universal en 1527. Distinción, jerarquía y prácticas sociales (con particular referencia a Guipúzcoa)», en VV.AA., El País Vasco, tierra de hidalgos y nobles. Momentos singulares de la historia, Madrid, Fundación Banco Santander, pp. 25-88.

Angulo Morales, Alberto (2015), «Los frutos de la movilidad. La emigración norteña peninsular en Madrid y el Imperio (siglos XVII y XVIII)», Obradoiro de Historia Moderna, 24, pp. 113-139. <https://doi.org/10.15304/ohm.24.2708>.

Angulo Morales, Alberto (2016), «Militares en las fronteras imperiales del Setecientos El ejemplo de los Regimientos de Cantabria y Navarra», en Sarmiento, Érica Pinheiro de Carvalho, Marieta y Flier, Patricia (coords.), $\mathrm{Mo}$ vimentos, Trânsitos \& Memórias. Temas e Abordagens, Niterói, ASOEC, pp. 981-994.

Aramburu Aburruza, Miguel de (2014), Nueva Recopilación de los fueros, privilegios, buenos usos y costumbres, leyes y ordenanzas de la muy noble y muy leal Provincia de Guipúzcoa (1696), San Sebastián, FEDHAV.

Areitio y Mendiolea, Darío de (1977), «Introducción», en El Fuero, privilegios, franquezas y libertades del M. N. y M. L. Señorío de Vizcaya, Bilbao, Diputación de Vizcaya.

Arrieta Alberdi, Jon (2014), «La persistencia del cantabrismo y otros tópicos historiográficos y jurídico-políticos en el País Vasco: adiciones en perspectiva comparada», en VV. AA., Historia iuris. Estudios dedicados al profesor Santos M. Coronas González, Oviedo, Universidad de Oviedo, vol. 1, pp. 351-377.

Arrieta, Jon, Gil, Xavier y Morales, Jesús (2017, coords.), La diadema del rey. Vizcaya, Navarra, Aragón y Cerdeña en la Monarquía de España (siglos XVI-XVIII), Bilbao, UPV/EHU.

Ayerbe IríbAr, María Rosa (2019), El primer derecho foral escrito de Álava y Guipúzcoa, Madrid, BOE.

Bilbao Bilbao, Luis Mª (1991), «Haciendas forales y hacienda de la Monarquía. El caso vasco, siglos XIV-XVIII», en VV.AA., Historia de la Hacienda en Espa$\tilde{n} a$ (siglos XVI-XX), Madrid, Instituto de Estudios Fiscales, pp. 43-58.

Bombín Pérez, Antonio (1999), «Servicios de la Provincia de Álava a la corona durante el reinado de Felipe II», en de Bernardo, José Manuel (coord.), Actas de la V Reunión Científica de la Asociación Española de Historia Moderna, Cádiz, Universidad de Cádiz, vol. 2, pp. 63-71. 
CÁrceles de Gea, Beatriz (1997), “'Voluntas e iurisdictio’: obediencia, ejecución y cumplimiento de la voluntad regia en la Corona de Castilla en el siglo XVII», en Fernández, Pablo (coord.), Actas de la IV reunión Científica de la Asociación Española de Historia Moderna, Alicante, Universidad de Alicante, vol. 1, pp. 663-677.

CARo BARoja, Julio (1989), «Sobre el árbol de Guernica y otros árboles con significado jurídico-político», en Caro Baroja, Julio, Ritos y mitos equívocos, Madrid, Istmo, pp. 353-391.

Chavarría Múgica, Fernando (2012), «Más allá de la Provincia: la función defensiva de Fuenterrabía como fundamento de sus prerrogativas en el entramado guipuzcoano y fronterizo (siglos XVI-XVIII)», en Jiménez, Antonio y Lozano, Julián J. (eds.), Actas de la XI Reunión Cientifica de la Fundación Española de Historia Moderna. Comunicaciones, vol. II, Granada, Universidad de Granada, pp. 986-996.

Clavero Salvador, Bartolomé (2012), «Gracia y derecho. Entre localización, recepción y globalización (lecturas corales de las vísperas constitucionales de António Hespanha», Quaderni Fiorentini per la storia del pensiero giuridico moderno, 41, pp. 675-763.

Correas, Gonzalo (1906), Vocabulario de refranes y frases proverbiales y otras fórmulas comunes de la lengua castellana, Madrid, Establecimiento Tipográfico de Jaime Ratés.

Díaz DE Durana, José Ramón (2020), «El reconocimiento de la hidalguía en la historiografía reciente. Sobre las diferencias entre los territorios y sus difusos contornos en época bajomedieval y altomoderna», en De la Torre, Sandra; Etxebarria, Ekaitz y Díaz de Durana, José Ramón (coords.), Valer más en la tierra. Poder, violencia y linaje en el País Vasco bajomedieval, Madrid, Sílex, pp. 283-308.

DíAz Noci, Javier (2003), «Del suceso a la fiesta. La construcción del acontecimiento en el Siglo de Oro español a través de las relaciones sobre el sitio de Fuenterrabía (1638)», en Paba, Antonia y Andrés, Gabriel (coords.), Encuentro de civilizaciones (1500-1750): informar, narrar, celebrar, Madrid, Universidad de Alcalá, pp. 129-148.

Elliott, John H., de la Peña, José Francisco. y negredo, Fernando (eds.) (2013), Memoriales y cartas del Conde Duque de Olivares, vol. I, Madrid, Marcial Pons.

Etxebarria Gallastegi, Ekaitz y Fernández de Larrea, Jon Andoni (2020), «"Guerrea espa baquea, gustia da enea". Cuantificación y propuesta de periodización de la violencia banderiza en los territorios vascos bajomedievales», en De la 
Torre, Sandra; Etxebarria, Ekaitz y Díaz de Durana, José Ramón (coords.), Valer más en la tierra. Poder, violencia y linaje en el País Vasco bajomedieval, Madrid, Sílex, pp. 179-205.

FLoRISTÁN IMízCOZ, Alfredo (1984), «Repercusión de la rebelión y guerra de Cataluña en Navarra. Las Cortes de 1642», en VV.AA., Primer congrès d'historia de Catalunya, vol. II, Barcelona, Universitat de Barcelona, pp. 181-187.

Frankenau, Gerardo Ernesto de (1993), Sagrados misterios de la justicia hispana, Madrid, Centro de Estudios Constitucionales, (ed. or. 1703).

García Martín, Javier (2017), «El Fuero de Vizcaya en la doctrina y la práctica judicial castellanas», en Arrieta, Jon; Gil, Xavier y Morales, Jesús (coords.), La diadema del rey. Vizcaya, Navarra, Aragón y Cerdeña en la Monarquía de España (siglos XVI-XVIII), Bilbao, UPV/EHU, pp. 53-168.

Gelabert, Juan E. (1997), La bolsa del rey. Rey, reino y fisco en Castilla (15981648), Barcelona, Crítica.

GonzÁlez Palencia, Ángel (1932), La Junta de Reformación. Documentos procedentes del Archivo Histórico Nacional y del General de Simancas, Valladolid, Tip. Poncelix.

Hespanha, António M. (1994-1995), «Las categorías de lo político y de lo jurídico en la época moderna», Ius Fugit. Revista interdisciplinar de estudios histórico-jurídicos, $\mathrm{n}^{\circ} 3-4$, pp. 63-100.

Imízcoz Beunza, José María (2009), «Las élites vasco-navarras y la Monarquía Hispánica: construcciones sociales, políticas y culturales en la Edad Moderna», Cuadernos de Historia Moderna, 33, pp. 89-119.

JimÉNEZ Estrella, Antonio (2009), «Las milicias en Castilla: evolución y proyección social de un modelo de defensa alternativo al ejército de los Austrias», en Ruiz, José Javier (coord.): Las milicias del rey de España. Sociedad, política e identidad en las Monarquías ibéricas, Madrid, FCE, pp. 72-103.

JimÉNeZ Estrella, Antonio (2015), «La historiografía militar sobre la España moderna en los últimos años», en Labrador, Félix (ed.), II Encuentro de Jóvenes Investigadores en Historia Moderna. Líneas recientes de investigación en Historia Moderna, Madrid, Universidad Rey Juan Carlos, pp. 13-48.

Laborda Martín, Juan José (2012), El Señorio de Vizcaya. Nobles y fueros (c. 1452 1727), Madrid, Marcial Pons.

LANDÁzURI, Joaquín José de (1799), Los varones ilustres alaveses, y los fueros, exenciones, franquezas y libertades que siempre ha gozado la M.N. y M.L. Provincia de Álava, Vitoria, Baltasar Manteli. 
LARreA, Juan Bautista (1665), Allegationum fiscalium, pars prima, Lyon, sumptibus Philippi Borde, Laurentii Arnaud, Petri Borde et Guill. Barbier.

Legarda, Padre Anselmo de (1953), Lo “vizcaíno” en la literatura castellana, San Sebastián, Biblioteca Vascongada de los Amigos del País.

Líbano Zumalacárregui, Ángeles (2016), Edición y estudio del Fuero de Vizcaya. El Fuero Antiguo (1342, 1394), el Fuero Viejo de Vizcaya (1452). Apéndice (1506), Leioa, UPV/EHU.

LóPEZ AtXuRRA, Rafael (1991), «La foralidad en la historiografía vasca», Ernaroa. Revista de historia de Euskal Herria, 6, pp. 117-170.

MacKay, Ruth (2007), Los límites de la autoridad real. Resistencia y obediencia en la Castilla del siglo XVII, Valladolid, Junta de Castilla y León.

MAfFi, Davide (2014), En defensa del imperio. Los ejércitos de Felipe IV y la hegemonía europea (1635-1659), Madrid, Actas.

Mañaricúa Nuere, Andrés (2012). Historiografía de Vizcaya, desde Lope García de Salazar a Labayru, Bilbao, Universidad de Deusto.

Martín Rodríguez, Jacinto (1968), «Figura histórico-jurídica del Juez Mayor de Vizcaya», Anuario de Historia del Derecho Español, 38, pp. 641-669.

Martínez Martínez, Faustino (2016), «Ius commune, Utrumque ius: Tiempos de Derecho único, tiempo de juristas», Glossae. European Journal of Legal History, 13, pp. 372-423.

Merino Malillos, Imanol (2017a), «Ecos de la matxinada. Negociaciones con la Corona y temor de tumultos en las Juntas Generales del Señorío de Vizcaya en torno a la crisis de la Monarquía Hispánica de 1640», Clio \& Crimen, 14, 2017, pp. 143-170.

Merino Malillos, Imanol (2017b), «"No se trata agora de sus fueros, sino de defenderlos en sus casas". El alojamiento del ejército de Cantabria en la frontera pirenaica occidental y los recursos de oposición locales (1638-1639)», Anuario de Historia del Derecho Español, 87, pp. 569-583.

Merino Malillos, Imanol (2017c), «Constitución de órganos colegiados para la administración de la guerra en territorios ibéricos durante los últimos años del ministerio del conde-duque de Olivares (1635-1643)», García, Enrique y Maffi, Davide (eds.), Estudios sobre guerra y sociedad en la Monarquía Hispánica: guerra marítima, estrategia, organización y cultura militar (1500-1700), Valencia, Albatros, pp. 539-570.

Merino Malillos, Imanol (2018), «“Ayunos del Fuero”». La distribución de ejemplares del Fuero Nuevo de Vizcaya por las instituciones provinciales vizcaínas (c. 1575-1700). Una aproximación», e-Legal History Review, 26, pp. 1-43. 
Monreal Zia, Gregorio (1980), «Anotaciones sobre el pensamiento político tradicional vasco en el siglo XVI», Anuario de Historia del Derecho Español, 50, pp. 971-1004.

Mugartegui Eguia, Isabel (1990), Hacienda y fiscalidad en Guipúzcoa durante el Antiguo Régimen, 1700-1814, San Sebastián, Fundación Cultural Caja de Guipúzcoa.

Pardo Molero, Juan Francisco (2001), La defensa del imperio. Carlos V, Valencia y el Mediterráneo, Madrid, Sociedad Estatal para la Conmemoración de los Centenarios de Felipe II y Carlos V.

Porres MariJuán, Rosario (2003), «De la Hermandad a la Provincia (siglos XVI-XVIII)», en Rivera, Antonio (dir.), Historia de Álava, San Sebastián, Nerea, pp. 185-306.

Porres MArijuán, Rosario (2007), «Discursos forales y fiscalidad real. Las provincias vascas ante el crecimiento de la sal», Studia Historica. Historia Moderna, 29, pp. 343-385.

PozA, Andrés de (edición de Carmen Muñoz de Bustillo, traducción de $\mathrm{M}^{\mathrm{a}}$ de los Ángeles Durán) (1997), Fuero de hidalguía. Ad Pragmaticas de Toro \& Tordesillas, Bilbao, UPV/EHU.

Rodríguez Hernández, Antonio José (2007), «Patentes por soldados. Reclutamiento y venalidad en el ejército durante la segunda mitad del siglo XVII», Chronica Nova, 33, pp. 37-56.

Rodríguez Hernández, Antonio José (2011), Los tambores de Marte. El reclutamiento en Castilla durante la segunda mitad del siglo XVII (1648-1700), Valladolid, Universidad de Valladolid.

Rodríguez Hernández, Antonio José (2012), «Servir al rey con hombres. Recompensas concedidas a élites y representantes del rey por su colaboración en el reclutamiento (1630-1700)», en Esteban, Alicia (ed.), Servir al rey en la Monarquía de los Austrias. Medios, fines y logros del servicio al soberano en los siglos XVI y XVII, Madrid, Sílex, pp. 415-443.

Rodríguez Hernández, Antonio José (2017), «El primer modelo de reclutamiento forzoso en España durante la Edad Moderna: las levas forzosas para los presidios (1634-1642)», Millars. Espai i historia, 43/2, pp. 151-167. < <https://doi. org/10.6035/Millars.2017.43.6>.

Ruiz Hospital, Gonzalo (1997), El gobierno de Gipuzkoa al servicio de su rey y bien de sus naturales. La Diputación provincial de los fueros al liberalismo (siglos $X V I-X I X)$, San Sebastián, Diputación Foral de Gipuzkoa. 
SaAvedra Vázquez, María del Carmen (2017), «El papel de las élites locales en la organización militar: Galicia, 1668-1715)», en García, Enrique y Maffi, Davide (eds.), Estudios sobre guerra y sociedad en la Monarquía Hispánica: guerra marítima, estrategia, organización y cultura militar (1500-1700), Valencia, Albatros, pp. 519-538.

SÁnchez BelÉn, José Antonio (1999), «La aportación de la provincia de Álava a la contienda hispano-portuguesa en los años finales del reinado de Felipe IV (1663-1665)», Espacio, Tiempo y Forma. Serie IV (Historia Moderna), 12, pp. 249-273. <https://doi.org/10.5944/etfiv.12.1999.3384>.

SORIa SESÉ, Lourdes (2006), «La hidalguía universal», Iura Vasconiae, 3, pp. 283-316.

Soria SEsÉ, Lourdes (2007), «La defensa militar en el ordenamiento jurídico foral. Preceptos constitutivos y actividad reglamentaria durante los siglos XVIII y XIX», Iura Vasconiae, 4, pp. 327-365.

Thompson, Irving A. A. (1981), Guerra y decadencia. Gobierno y administración en la España de los Austrias, 1560-1620, Madrid, Crítica.

Truchuelo García, Susana (2004), Gipuzkoa y el poder real en la alta Edad Moder$n a$, San Sebastián, Diputación Foral de Gipuzkoa.

Truchuelo García, Susana (2007), «El deber de servicio militar al monarca: el caso alavés y guipuzcoano (siglos XVI-XVII)», Iura Vasconiae, 4, pp. 239-285.

Truchuelo García, Susana (2013), «Gobernar territorios en tiempo de guerra: la mediación de las oligarquías en la Monarquía de los Habsburgo», Revista Escuela de Historia, 12/1, s.p.

Truchuelo García, Susana (2015), «Fontarabie en 1638. Conflits et consensus dans la défense de la frontière espagnole», en Boltanski, Ariane; Lagadec Yann y Mercier, Franck (dirs.), La bataille. Du fait d'armes au combat idéologique XIe-XIXe siècle, Rennes, Press Universitaires de Rennes, pp. 171-186. <https://doi.org/10.4000/books.pur.90940>.

Truchuelo García, Susana (2017), «Irún y Hondarribia. Una controvertida historia de discrepancias y consensos», Boletín de Estudios del Bidasoa, 29, pp. 83-102.

Valladares Ramírez, Rafael (2012), «El problema de la obediencia en la Monarquía Hispánica, 1540-1700», Esteban, Alicia (ed.), Servir al rey en la Monarquía de los Austrias. Medios, fines y logros del servicio al soberano en los siglos XVI y XVII, Madrid, Sílex, pp. 121-145.

Vitores CAsado, Imanol (2019), Poder, sociedad y fiscalidad en el Señorío de Vizcaya durante la Baja Edad Media, Oñati, IVAP. 
Volpini, Paola (2010), El espacio político del letrado. Juan Bautista de Larrea, magistrado y jurista en la monarquía de Felipe IV, Madrid, UAM.

VV.AA. (2015), Censo de la Sal, 1631, vol. I (Vecindario), Madrid, INE.

Zabala Montoya, Mikel (2014), «Los orígenes de la Diputación de Bizkaia: de los diputados generales a la Diputación General», en Agirreazkuneaga, J. (ed.) (2014), Historia de la Diputación Foral de Bizkaia. 1500-2014, Bilbao, Diputación Foral de Bizkaia. 